9 - ORIGINAL ARTICLE

ISCHEMIA-REPERFUSION

\title{
Hystopathological study of the intestinal epithelium submitted to different times of programmed ischemia and twenty four hours reperfusion ${ }^{1}$
}

\author{
Ana Terezinha Guillaumon ${ }^{\mathrm{I}}$, Murillo Antonio Couto ${ }^{\mathrm{II}}$ \\ IFull Professor and Head, Vascular Diseases Division, Department of Surgery, Faculty of Medical Sciences, UNICAMP, Campinas-SP, Brazil. \\ Coordinator, Laboratory of Microprocedures and Vascular Research, Center for Experimental Medicine and Surgery, UNICAMP. Analysis and \\ interpretation of data, manuscript writing, critical revision

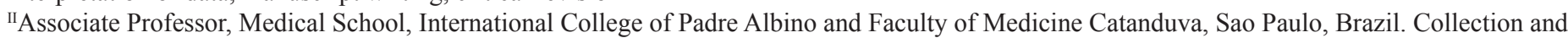 \\ processing of the study informations, manuscript writing.
}

\section{ABSTRACT:}

PURPOSE: To investigate the changes in the intestinal epithelium of rats, when submitted to the ischemia of varied time and scheduled reperfusion.

METHODS: For this purpose, the following groups were established six groups: control, 10, 20, 30, 40, 60 minutes of ischemia and reperfusion time ( 24 hours). Their intestines being resected for histopathological analysis: the length and width of the villus, and mitotic index. The nonparametric test Kruskal-Wallis and multiple comparisons test were applied.

RESULTS: The qualitatively the intestinal epithelium is regenerated when submitted to different ischemia, and 24 hours reperfusion time. It was observed that morphometry analyzing taking villus length and width and mitotic index as parameter, meaningful alterations were detected.

CONCLUSION: The epithelium is regenerated, when subjected to different time planned of ischemia and reperfusion. It was observed: decrease the length and increase the width of the villi, when compared Group VI with I and II, and Group VI with I; increased mitotic index when compared Groups III with I. Every analysis was statistically significant.

Key works: Ischemia. Reperfusion. Intestinal Mucosa. Rats. 


\section{Introduction}

Changes that occur in the intestinal epithelium due to ischemia and reperfusion (IR) have been the subject of countless studies. Among these studies, the histopathological changes that occur in the intestinal epithelium after periods of IR have been described by several authors ${ }^{1}$. It should be emphasized, however, that most of these studies aimed the evaluation of the changes and their consequences in programmed ischemia and reperfusion in short periods of time and always less than 24 hours.

Other studies have demonstrated the importance of biochemical processes knowledge for a better

understanding of the reactions triggered after a period of ischemia and reperfusion ${ }^{2}$. More recently, these studies made possible the use of drugs that could act systematically in the intestine minimizing the harmful consequences caused by the $\mathrm{IR}^{3}$.

According to evidence, it is relevant to evaluate the qualitative and quantitative (morphometric) histopathological changes of the villus, as well as the occurrence of the intestinal epithelium reconstitution by the mitotic index, after using the process of different times of ischemia and 24 hours reperfusion.

Acute mesenteric ischemia is the absence or severe reduction of blood flow due to arterial, venous or intestinal microcirculation damage. Through reperfusion and an increase in cell permeability, oxygen becomes available again causing oxidation in the metabolites and the emergence of free radicals which leads to tissue damage and other injuries in the system ${ }^{4,5}$.

The study of various authors about the mechanism of ischemia and reperfusion injury and histological changes has showed that injuries caused by the decrease of the flow occurred from the villus to the crypt, and also that the villus had greater sensitivity to ischemic process, with injuries to more serious levels ${ }^{5-10}$.

So in 1982, Parks ${ }^{11}$ observed that the top of the villus of the intestinal mucosa has greater sensitivity to the free radicals action than the phenomenon hypoxic itself. Horton et al. ${ }^{12}$ noted that oxygen free radicals produced during ischemia and reperfusion contribute to lipid oxidation of cell membrane and prevent increased permeability of the mucosa, possibly making bacterial translocation and sepsis more potent.

Grisham ${ }^{13}$ and Kubes ${ }^{14}$ found evidence of biochemical changes and the presence of an inflammatory response of the intestinal epithelium compared to the IR process due to a significant adhesion and extravasation of leukocytes. Given this verified fact, some authors studied the importance and influence of oxygen free radicals in the injury occurred due to the ischemia and reperfusion.
The use of drugs in mesenteric ischemia after mesenteric artery occlusion: angiotensin II, chelants of free radicals, vasopressin, allopurinol (GII), superoxide dismutase (GIV), tocopherol, ascorbate, adenosine (ADO), heparin (HEP), ketamine and oxipurinol prevent damage caused during ischemia and also extend the bowel tolerance to ischemia and reperfusion ${ }^{3,15-28}$.

The importance of experimental studies with Wistar rats is evidenced by the description of many mechanisms involved in the lesions and histopathological changes caused by ischemia and reperfusion. The aim of this study is to observe the changes in the intestinal epithelium of rats, when submitted to the ischemia of varied time and scheduled reperfusion

\section{Methods}

The maintenance of experimental animals in the Animal Center of Experimental Medicine and Surgery - NMCE School of Medical Sciences, followed the criteria of scheduled replacement of beds, balanced feed and water ad libtum in conventional environment, with controlled temperature according to good practices in animal houses.

The Ethics Committee of Animal Experimentation EAEC INSTITUTE OF BIOLOGY approved the experimental procedures under the protocol number 133-1.

The experimental protocol used 30 Wistar heterogeneous rats, divided into six groups of five male animals, with mean age of 39.7 days and an average weight of 244 grams. The animal selection was judicious and it excluded those who had physical changes compatible with possible undesirable conditions such as peeling of the skin, eye discharge, hair loss and behavior not compatible to animal welfare.

The animals were randomly divided into six groups of five animals:

GROUP I - Control

GROUP II - Group 10 minutes ischemia

GROUP III - Group 20 minutes ischemia

GROUP IV - Group 30 minutes ischemia

GROUP V - Group 40 minutes ischemia

GROUP VI - Group 60 minutes ischemia

All animals underwent surgery consisted of intestinal ischemia by placing a vascular hemostatic clamp in the superior mesenteric artery, according to predetermined times for each group. Following this procedure the reperfusion of the intestine was performed, just after the removal of clamps and release of the mesenteric artery flow. After the period of 24 hours, the animals were euthanized with an intestinal biopsy for collection of 
pathologic analysis.

The experiment was conducted in the animal house of Microprocedures and Vascular Research Center for Experimental Medicine and Surgery, Medical Sciences School, State University of Campinas (UNICAMP). The preparation of the operative field included shaving hair and antisepsis with iodine alcohol $2 \%$ after the anesthetic procedure and fixing plate heated to $37^{\circ} \mathrm{C}$.

The anesthetic used was sodium Thiopental $<2 \%$ at a dose of $30 \mathrm{mg} / \mathrm{kg}$ / body weight, intravenous flow, emphasizing that the same anesthetic was used in all groups, so it was not necessary to perform anesthetic supplementation.

The operative procedure was carried out through laparotomy, opening the plans of the wall, anterior and posterior peritoneum (Figure 1).

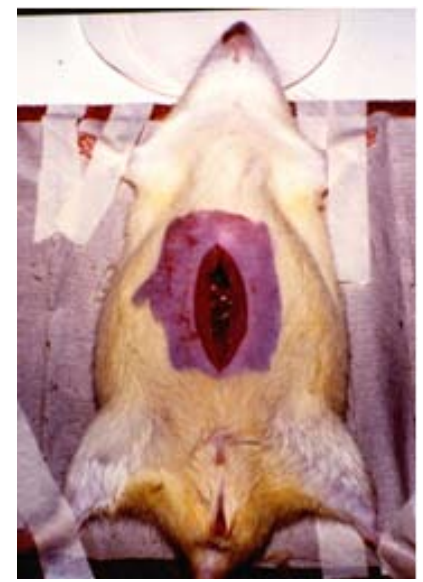

FIGURE 1 - Opening of Animal Model with abdominal cavity.

The handles were exposed with exteriorization of the abdominal cavity. Once located, the superior mesenteric artery dissection was performed. Vascular hemostatic forceps were used for clamping the superior mesenteric artery according to the predetermined duration of ischemia for each group respectively (Figures 2 to 5 ).

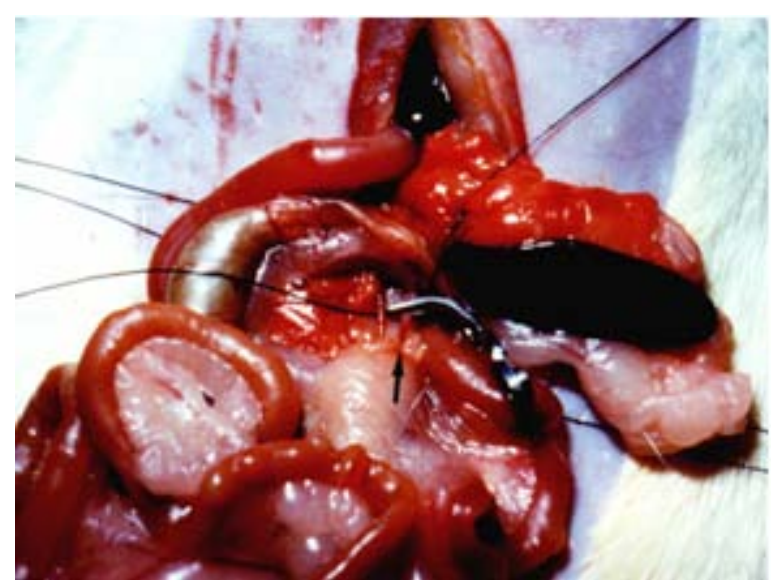

FIGURE 2 - Isolation and clamping the superior mesenteric artery TROUGH VASCULAR a hemostat - seta.

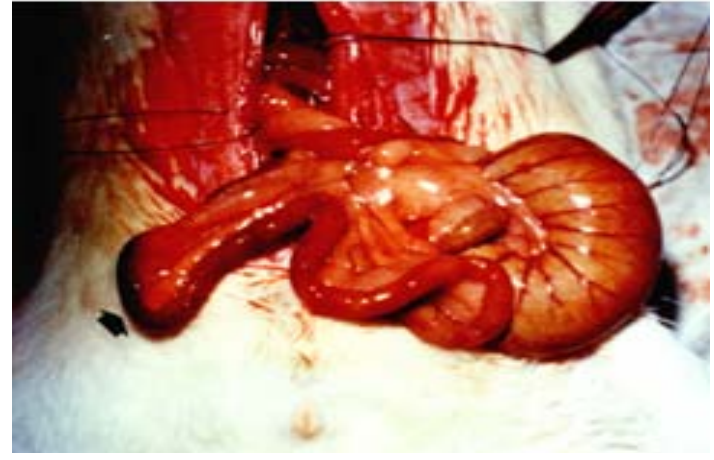

FIGURE 3 - 10 MINUTES ISCHEMIA - RED WINE STAIN of the proximal small bowel (arrow).

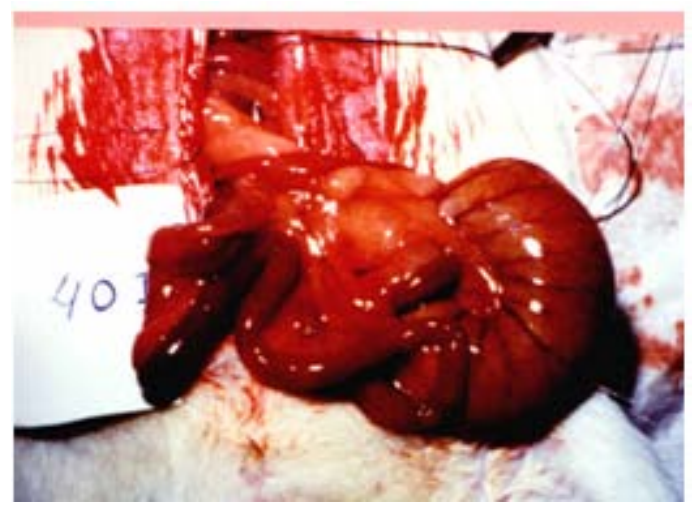

FIGURE 4 - SMALL INTESTINE AFTER 40 minutes of ischemia STAIN dark (arrow).

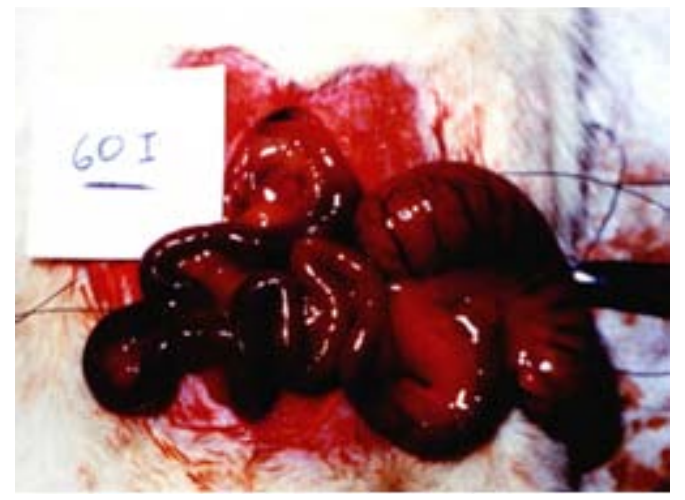

FIGURE 5 - SMALL INTESTINE AFTER 60 minutes of ischemia.

After determining clamping time, vascular hemostatic clamp was withdrawn from the superior mesenteric artery with replacement of the bowel into the abdominal cavity and closure of the peritoneum, aponeurosis and skin, in layers.

During the intra-operative phase, mesenteric ischemia was performed with pre-determined times to the different groups. In Group I - considered the control group - we only performed the opening of the abdominal cavity in layers of exposure of the handles, dissection of the artery and closure in layers. In Group II, we did the same surgical procedure than in group I, but we did the dissection and placement of hemostatic clips in superior 
mesenteric artery for 10 minutes. After this time, we made the unclamping of the superior mesenteric artery with subsequent closure in layers.

In Groups III, IV, V and VI we followed the same technique of the previous groups except for group I, with clamping of the superior mesenteric artery during 20, 30, 40, 60 minutes respectively.

The animals were kept in individual cages with solid and liquid diet ad libitum. After completing 24 hours of the first surgery, they were anesthetized via inhaled ether (update anesthetic methodology abolishing the use of ether-2000) and reoperated by the same team, adopting the same technique in order to make the collection of the necessary material for evaluation.

After re-laparotomy the identification of the cecal ileum valve was carried out and subsequent bowel resection. The collection of all pieces of intestine (jejunum) always obeyed the anatomical arrangement of the irrigation of vascular arcades, from caudal to cranial and from ileum to jejunum. The material was preserved in buffered formalin.

After collection and biopsies, the animals were sacrificed with a lethal dose of ether, as recommended by the Brazilian College of Animal Experimentation, within ethical standards (Update methodology abolishing the use of anesthetic ether).

The fragments of intestine were carefully selected according to the description of the item "collection of material ", washed in $0.9 \%$ saline solution, opened in their anti-mesenteric border and stretched on small cork plates with the mucosa exposed and their four borders tied up with pins. After these procedures, the fragments were placed in Carnoy solution for six hours to be fixed. Following that, the fragments were processed according to routine methods for optical microscopy. Histological sections of five micrometers thick were dyed by hemalúmen and then by eosin.

The cuts assembly on each slide was made as follows: we chose the first cut of paraffin queue then we discarded the subsequent five cuts and we set up the seventh. This procedure was successively done until obtaining five cuts per slide. The purpose of this assembly was the detection of microscopic findings distinct from one another, for morphometric evaluations.

\section{Qualitative histological evaluation}

During ischemia and the period of blood flow restoration, intestinal mucosal lesions (reperfusion injury) were evaluated by analysis of histological sections, at different times of ischemia and reperfusion, in all animals belonging to six groups - DOUBLEBLIND. Inflammation and necrosis of intestinal villus and crypts were graded according to the classification proposed by Granger et $a l .{ }^{25}$ as described below:

$$
\text { a - Villus }
$$

0 - no injury

$1-$ lesion on the tip of rare villus

2 - injury at the end of most villus

3 - injury at the end of most villus and the measuring middle portion of 10 villus

4 - injury in the end of middle and lower portions of most villus

$$
\text { b - Crypts }
$$

0 - no injury

1 - injury of rare crypts $(<10 \%)$

2 - injury of sparse crypts $(>10 \%$ and $<75 \%)$

3 - injury of many crypts ( $>50 \%$ and $<75 \%)$

4 - injury of most crypts (75\%)

\section{Quantitative histological evaluation}

With the aid of an ocular 8x, a graduated scale and a 10x objective, the measurement was made in ten well-oriented villus (cut across its length) in each of the animals at different times of ischemia.

After measuring these structures, we proceeded calibrating the scale of the ocular with a slide fitted with special divisions of $0.01 \mathrm{~mm}$ (10um), in order to transform the measures (taken in units of the ocular) in micrometers so we could properly express the dimensions of the structures mentioned in the metric system.

The mitotic index (MI) is the percentage of nucleus in mitosis of a given cell population compared to those in interphase. This was obtained by counting 100 cells in the middle and/ or bottom of the intestinal glands (intestinal crypts) and writing down how many nucleus of these 100 cells were in mitosis. For each animal of the different groups were counted 500 cells of five microscopic fields, randomly taken.

\section{Statistical analysis}

To evaluate possible differences between the groups previously defined for the various lengths, widths and mitotic indexes of the villus, we used a nonparametric test for KruskalWallis averages. It should be noted that when there was statistical 
significance, we supplemented this test adopting the test of multiple comparisons.

The significance level for the rejection of the nullity hypothesis was set, always in a value less than or equal to 0.05 $(5 \%)$.

When the calculated statistic presented significance, we used an asterisk $(*)$ to characterize it.

The averages were calculated and presented for information purposes only. With the use of nonparametric statistical test, we assumed that the variables under study do not behave like a Gaussian curve. So, it makes sense to calculate the standard deviation ${ }^{25,26}$.

\section{Results}

\section{Qualitative histological evaluation}

In the intestinal samples belonging to different groups of animals we verified a complete regeneration of the intestinal mucosa after a 24 hours reperfusion (Figure 6).

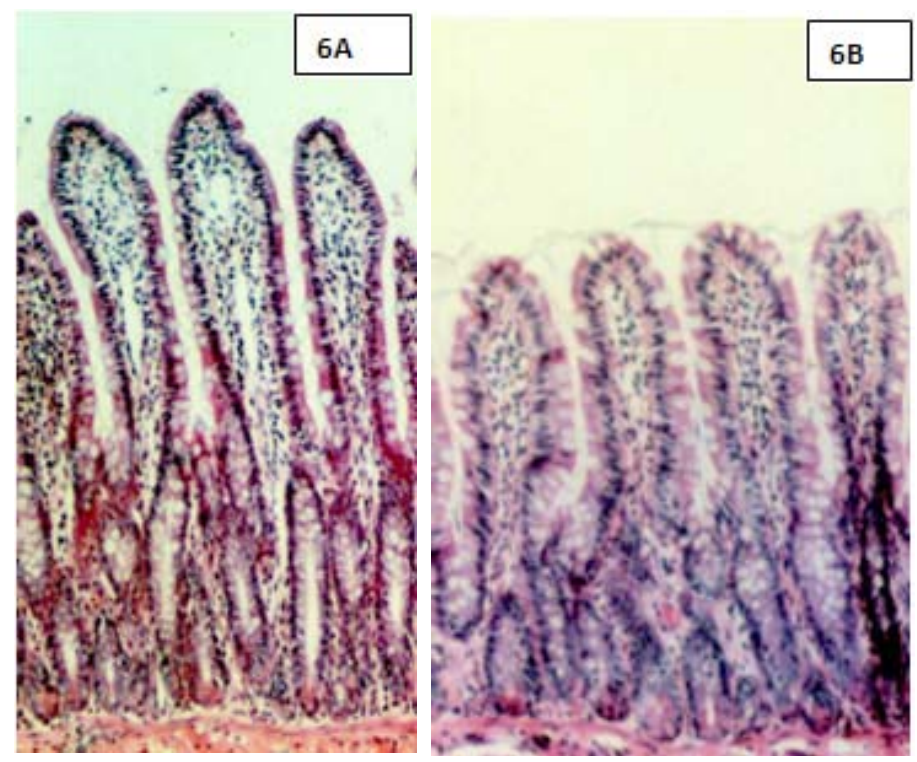

FIGURE 6 - Photomicrography. A. Intestinal villus of animals from Group I (Control) with hematoxylin-eosin (HE) coloration (100x). B. Intestinal villus of animals from Group III submitted to 20 minutes of ischemia (HE, 100x).

\section{Quantitative histological evaluation (morphometry)}

In the morphometric analysis of the intestinal villus of the different groups we observed a reduction in its length, as we increased the time of ischemia. This reduction in villus length was statistically significant when comparing to the villus that underwent 60 minutes of ischemia (group VI) in relation to the control group (no ischemia) and to the villus that underwent 10 minutes of ischemia (group II). (Tables 1 and 2, Figures 7 and 8).

TABLE 1 - Length of intestinal villus $(\mu \mathrm{m})$ of animals submitted to progressive increase of ischemia time according to group I (control), group II (10 minutes), group III (20 minutes), group IV (30 minutes), group V (40 minutes) and group VI (60 minutes).

\begin{tabular}{ccccccc}
\hline Group & I & II & III & IV & V & VI \\
\hline & 287 & 275 & 249 & 193 & 211 & 166 \\
& 275 & 277 & 216 & 196 & 219 & 172 \\
$\begin{array}{c}\text { Length of } \\
\text { intestinal villus } \\
\text { in } \mu \mathrm{m}\end{array}$ & 286 & 251 & 176 & 181 & 190 & 170 \\
& 274 & 243 & 203 & 187 & 166 & 174 \\
\hline Average & 280.60 & 261.40 & 217.80 & 189.30 & 196.50 & 170.20 \\
\hline
\end{tabular}

$\mathrm{ND}=$ Not determined

$\mu \mathrm{m}=$ milimicras

The dates were been submitted to statistical analysis for the Kruskal-Wallis test and multiple comparisons test. The Kruskal-Wallis test showed these results: Hcrit $=11.07$ (critical length)

Hcalc $=22.54$ (calculated length estimated $\geq$ critical statistically significant $)$ Hcorr $=22.55$ (corrected length)

Multiple comparison tests have been done to complete the analysis of the results of this experimental study and demonstrated statistical significance difference.

TABLE 2 - Multiple comparison test analyzing the morphometry compared of the villus.

\begin{tabular}{ccc}
\hline Pairs & VADMP & MSD \\
\hline I, II & 4.00 & 15.27 \\
I, III & 10.90 & 15.27 \\
I, IV & 15.30 & 16.20 \\
I, V & 14.93 & 16.20 \\
I, VI & $21.40^{*}$ & 15.27 \\
II, III & 6.90 & 15.27 \\
II, IV & 11.30 & 16.20 \\
II, V & 10.93 & 16.20 \\
II, VI & $17.40^{*}$ & 15.27 \\
III, IV & 4.40 & 16.20 \\
III, V & 4.03 & 16.20 \\
III, VI & 10.50 & 15.27 \\
IV, V & 0.38 & 17.07 \\
IV, VI & 6.10 & 16.20 \\
V, VI & 6.48 & 16.20 \\
\hline VADMP & difference & between \\
minimum significant difference & median \\
\hline MSD & & \\
\hline
\end{tabular}




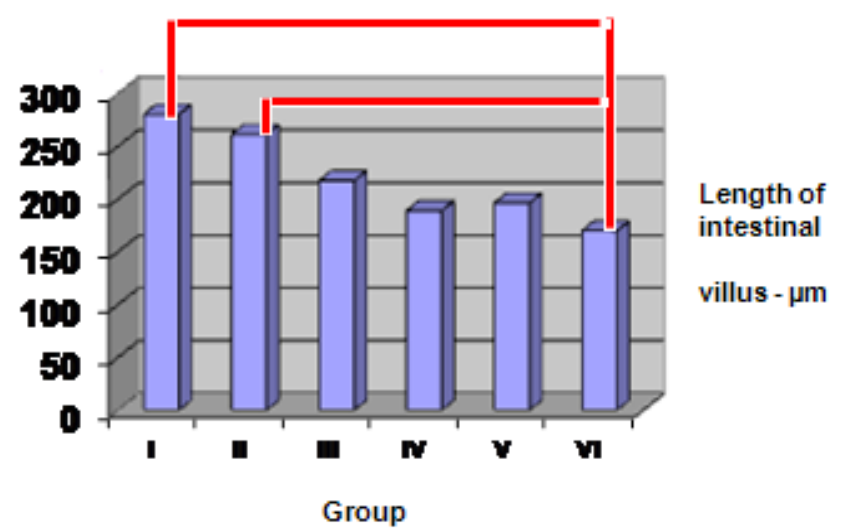

FIGURE 7 - Average length of intestinal villus - $\mu \mathrm{m}$ (in relation to groups).

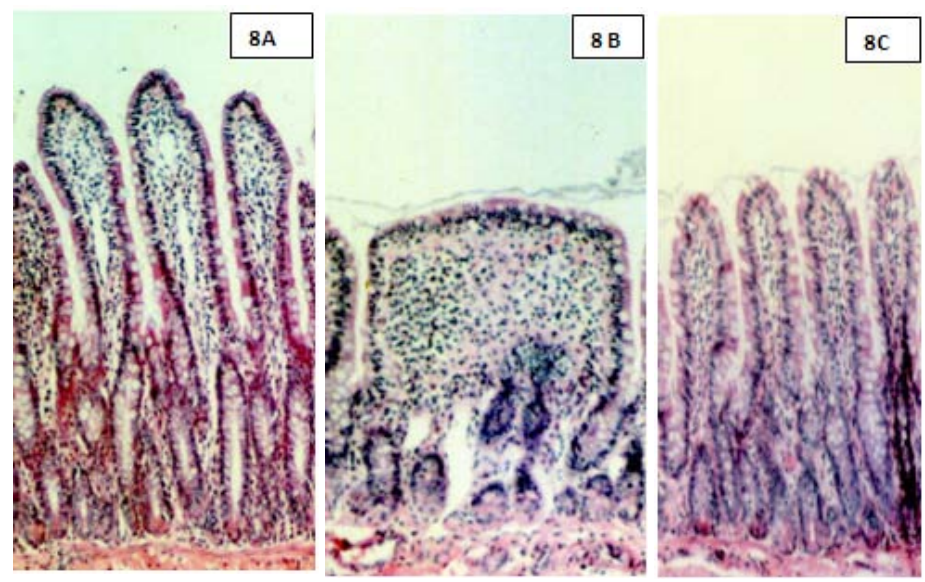

FIGURE 8 - A. Intestinal villus of animals from group I (control) with hematoxylin-eosin (HE) coloration; B. Intestinal villus of animals from group VI submitted to 60 minutes of ischemia (HE, 100x); C. Intestinal villus of animals from group II submitted to 10 minutes of isquemia (HE, $100 \mathrm{x})$.

Comparing Group IV (30 minutes ischemia) and Group $\mathrm{V}$ (40 minutes ischemia) to the control group, the results also suggest that the value of the statistic is close to the critical value: (15.3 to 16.2) and (14.93 to 16.2) respectively.

When analyzing the width of the intestinal villus, we observed an enlargement of its area. It should be highlighted that such enlargement is significant when group VI (60 minutes ischemia) was compared to the control group (group I) (Tables 3 and 4, Figures 9 and 10).
TABLE 3 - Intestinal villus width $(\mu \mathrm{m})$ of animals submitted to a progressive increase in ischemia time, according to group I (control), group II (10 minutes), group III (20 minutes), group IV (30 minutes), group V (40 minutes) and group VI (60 minutes).

\begin{tabular}{ccccccc}
\hline Group & I & II & III & IV & V & VI \\
\hline & 77.00 & 99.00 & 89.00 & 89.00 & 75.00 & 90.00 \\
$\begin{array}{c}\text { Width } \\
\text { of the } \\
\begin{array}{c}\text { intestinal } \\
\text { villus }\end{array}\end{array}$ & 75.00 & 83.00 & 90.00 & 87.00 & 93.00 & 89.00 \\
& 73.00 & 78.00 & 78.00 & 82.00 & 93.00 & 91.00 \\
\hline Average & 75.00 & 83.60 & 84.80 & 86.50 & 84.50 & 90.00 \\
\hline
\end{tabular}

$\mathrm{ND}=$ Not determined

The dates were been submitted to statistical analysis for the Kruskal-Wallis test and multiple comparisons test. Kruskal-Wallis Test showed this results: Hcrit - 11.07 ( critical width)

Hcalc $=13.52$ (calculated width estimated $\geq$ critical statistically significant) Hcorr $=13.60$ (corrected width)

TABLE 4 - Multiple comparison Test analyzing the width of the villus.

\begin{tabular}{ccc}
\hline PAIRS & VADMP & MSD \\
\hline I, II & 10.60 & 15.27 \\
I, III & 11.70 & 15.27 \\
I, IV & 12.43 & 16.20 \\
I, V & 11.93 & 16.20 \\
I, VI & $8.70^{*}$ & 15.27 \\
II, III & 1.10 & 15.27 \\
II, IV & 1.82 & 16.20 \\
II,V & 1.32 & 16.20 \\
II,VI & 8.10 & 15.27 \\
III,IV & 0.72 & 16.20 \\
III,V & 0.22 & 16.20 \\
III,VI & 7.00 & 15.27 \\
IV, V & 0.50 & 17.07 \\
IV, VI & 6.27 & 16.20 \\
V. VI & 6.77 & 16.20 \\
\hline
\end{tabular}

VADMP $=$ calculated difference between the median posts $\mathrm{MSD}=$ minimum significant difference 


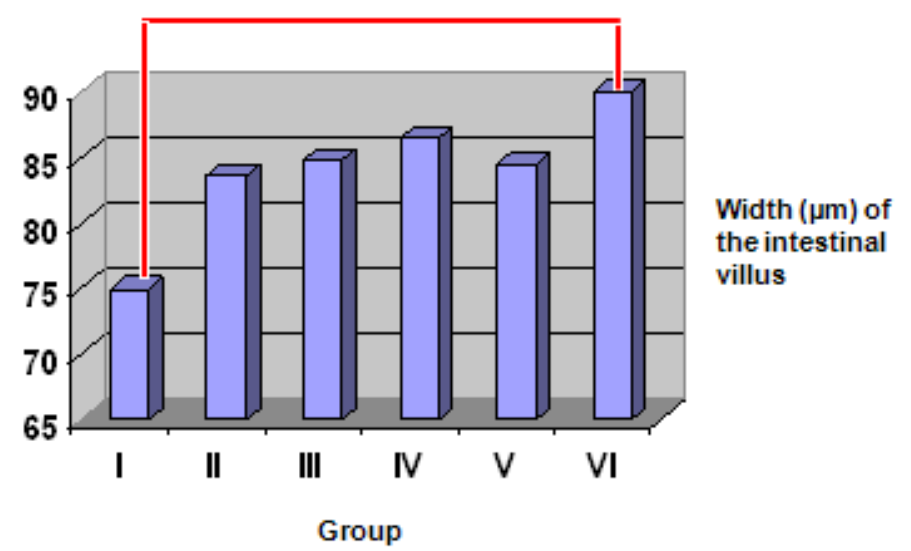

FIGURE 9 - Average width $(\mu \mathrm{m})$ of the Intestinal villus in relation to groups.

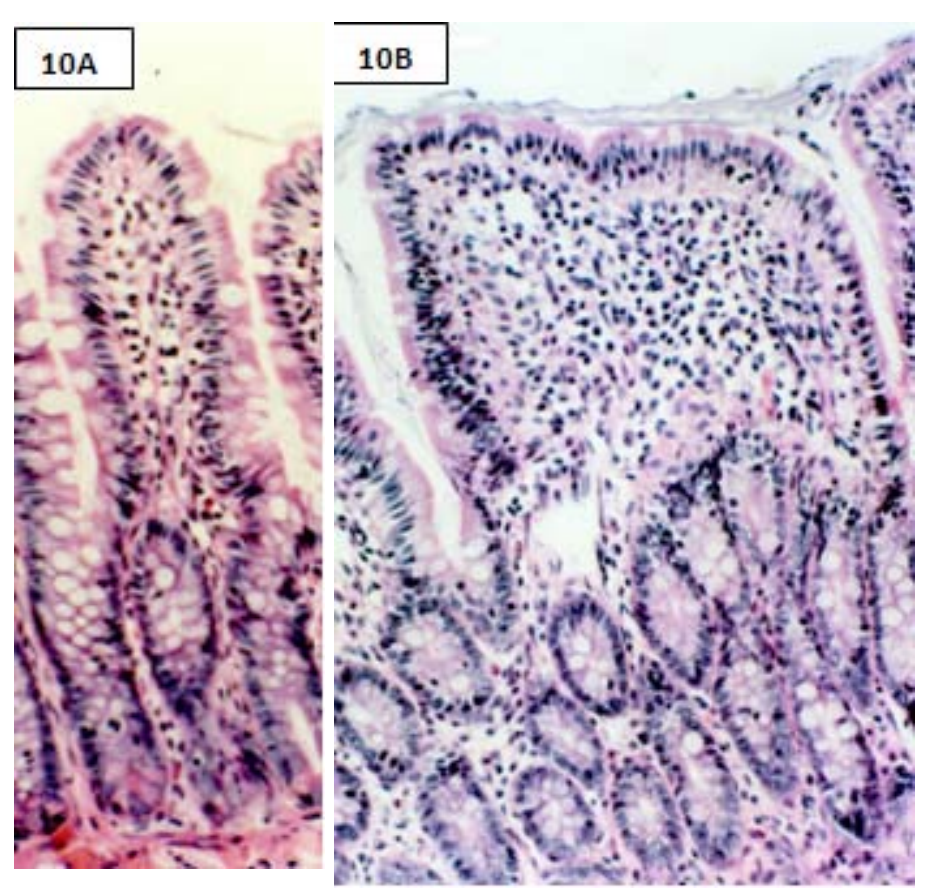

FIGURE 10 - A. Intestinal villus of animals from group I (control), absence of ischemia (HE, 256x). B. Intestinal villus of animals from group VI submitted to 60 of ischemia (HE, 256x).

When observing the mitotic index of the villus from different groups, we found an increased percentage of nucleuses in mitosis in the groups that suffered ischemia when compared to the control group (Tables 5 and 6, Figures 11 and 12).

However, statistical analysis found a significant difference in the comparison between group III (20 minutes ischemia) and the control group.
TABLE 5 - Mitotic index of the intestinal villus (\%) of animals submitted to a progressive increase in ischemic time, according to group I (control), group II (10 minutes), group III (20 minutes), group IV (30 minutes, group V (40 minutes) and group VI (60 minutes).

\begin{tabular}{ccccccc} 
Group & $\mathbf{I}$ & $\mathbf{I I}$ & $\mathbf{I I I}$ & $\mathbf{I V}$ & $\mathbf{V}$ & $\mathbf{V I}$ \\
\hline $\begin{array}{c}\text { Mitotic } \\
\text { index } \\
\text { of the }\end{array}$ & 4.00 & 9.00 & 10.00 & 9.00 & 9.00 & 9.40 \\
$\begin{array}{c}\text { intestinal } \\
\text { villus }\end{array}$ & 3.80 & 9.60 & 9.40 & 10.40 & 9.80 & 10.40 \\
& 4.60 & 11.00 & 11.20 & $\mathrm{ND}$ & $\mathrm{ND}$ & 9.40 \\
\hline Average & 4.04 & 9.68 & 10.24 & 10.20 & 10.10 & 10.12 \\
\hline
\end{tabular}

$\mathrm{ND}=$ Not determined

The dates were been submitted to statistical analysis for the Kruskal-Wallis test and multiple comparisons test.

Hcrit $\quad-\quad 11.07 \quad$ (critical mitotic index) Hcalc $=12.96($ calculated mitotic index estimated $\geq$ critical statistically significant $)$ Hcorr $=13.11($ corrected mitotic index $)$

TABLE 6 - Multiple-comparison test of the Mitotic Index.

\begin{tabular}{ccc}
\hline Pairs & VADMP & DMS \\
\hline I, II & 10.70 & 15.27 \\
I, III & $15.40^{*}$ & 15.27 \\
I, IV & 15.13 & 16.20 \\
I, V & 14.63 & 16.20 \\
I, VI & 14.50 & 15.27 \\
II, III & 4.70 & 15.27 \\
II, IV & 4.43 & 16.20 \\
II, V & 3.93 & 16.20 \\
II, VI & 3.80 & 15.27 \\
III, IV & 0.27 & 16.20 \\
III, V & 0.77 & 16.20 \\
III, VI & 0.90 & 15.27 \\
IV, V & 0.50 & 17.07 \\
IV, VI & 0.63 & 16.20 \\
V, VI & 0.13 & 16.20 \\
\hline
\end{tabular}

VADMP $=$ calculated difference between the median posts $\mathrm{MSD}=$ minimum significant difference 


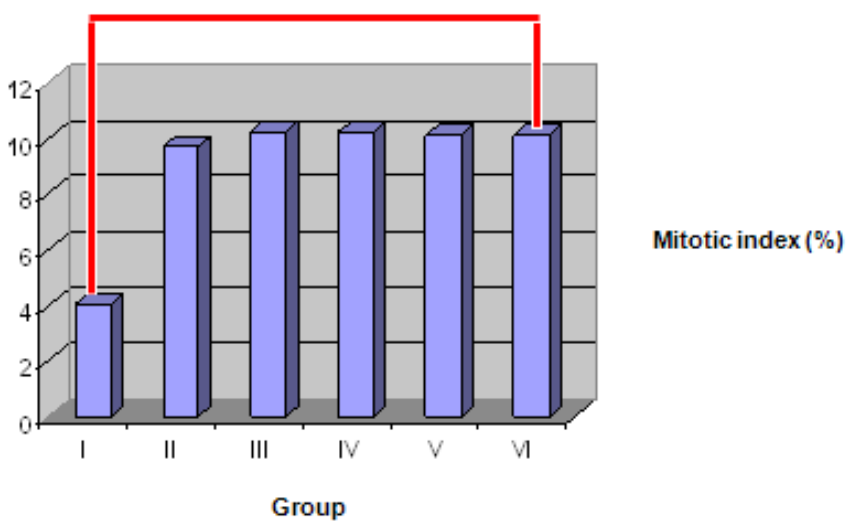

FIGURE 11 - Average of the Mitotic Index (\%) of intestinal villus towards the groups.

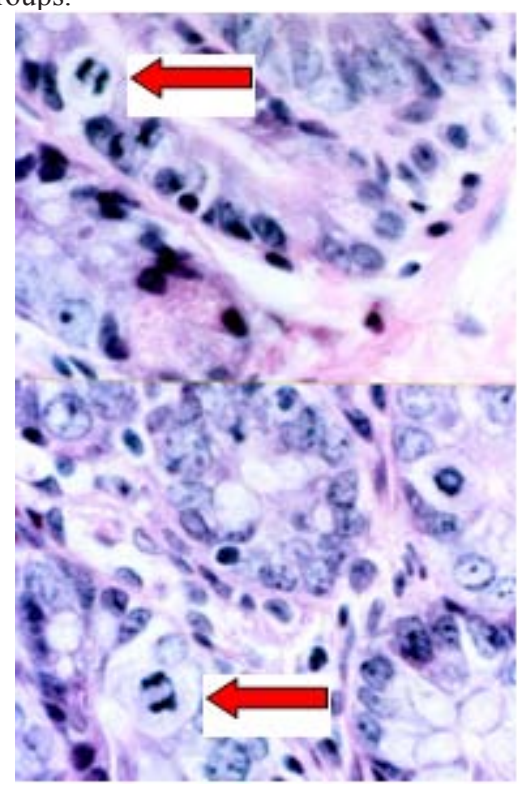

FIGURE 12 - Intestinal villi Animal Group III undergoing 20 minutes of ischemia (HE, 1024x). Myths in figures (arrow).

\section{Discussion}

The changes caused by ischemia and reperfusion process in the intestine made several authors develop studies on this topic. These studies found that lesions in the intestinal epithelium and their histopathological changes are proportional to the time of exposure of these tissues to ischemia ${ }^{4,27-31}$.

Haglund et $a .^{5}$ found it possible to detect changes in the endoplasmic reticulum with ischemia of 10 minutes. After 15 minutes of ischemia the mucosa of the intestinal epithelium showed changes in its structure and after 30 minutes of ischemia basal membranes were compromised, indicating a rise in the intra and extra-cellular spaces, with intense lesions at the top of the villus.
The qualitative changes that occurred in the intestinal epithelium after the ischemia process were observed by some authors. According to these authors, the injury caused by the process of ischemia - reperfusion would follow the direction intestinal villus to the crypt, and that the villus showed a greater sensitivity to ischemia ${ }^{4-6}$.Serious injury occurs, also, during the reperfusion, more intensive and in more levels ${ }^{7-9}$. Lundgren ${ }^{10}$ suggest that the injury caused by ischemia would be more intense in the villus because the decreased blood flow and oxygenation occurs from the top of the villus to the crypt. Bounus ${ }^{32}$ observed that the reduction of the mucosa is proportional to ischemia time, and more intense during the reperfusion phase. Thus, it is known that the epithelium is reconstructed in the reverse direction, in other words, from the crypt to the villus.

The intestinal villus is the last portion of the epithelium to regenerate after ischemia, when analyzed qualitatively. It is known that regeneration of the epithelium is intense and that for a scheduled 10-minute ischemia and it was found almost complete regeneration around three hours of reperfusion ${ }^{14,26,33}$.

In the presented work, the exposure of the intestinal epithelium was performed at various times of ischemia, increasing it gradually. Reperfusion was maintained without variation for the different groups (24 hours). Initially, the regeneration was qualitatively evaluated and the result was that according to the classification of Granada the regeneration was full in the different groups of ischemia. However, when considering the morphometric parameters significant changes were observed such as decreased length of villus, increased width and increased mitotic index.

When evaluating the length of the intestinal villus, we observed that the villus in group II (10 minutes ischemia), in group III (20 minutes ischemia), in group IV (30 minutes ischemia) and in group V (40 minutes ischemia) showed no statistically significant decrease in villus length when compared to group I (control). But group VI (60 minutes ischemia) presented significant decrease of the length of the villus, when compared to group I. In this morphometric analysis, it was also observed that when comparing the reduction of the length found in group IV (30 minutes ischemia) and group V (40 minutes ischemia) to the control group (no ischemia), these values are close to the value of statistical significance (15.30 to 16.20$)$ and (14.93 to 16.20), respectively, suggesting a significant decrease in length. When evaluating the decrease in intestinal villus length between groups subjected to ischemia and no more to the control group we observed that: group II (10 minutes ischemia) presents no statistical significance difference in the length of the villus when compared to the group III (20 minutes), group IV (30 minutes) 
and group V (40 minutes). However, when comparing the length of the villus in group II (10 minutes) to group VI (60 minutes), the latter had a statistically significant decrease in the length of the villus. Group III (20 minutes ischemia) showed no significant difference in the length of the villus when compared to the other groups (II, IV, V, VI). Group IV (30 minutes ischemia) showed no statistically significant difference compared to groups (III, IV and V), however, as given above, it has presented a significant decrease in the length of the villus when compared to the vilus of group II.

When the width parameter was analyzed, it was observed that the villus of the group VI showed a statistically significant increase in width when compared to group I (control). The villus in groups II, III, IV and V did not show a statistically significant increase when compared to group I (control). By comparing the width measurement between the groups subjected to ischemia, excluding the control, no significant differences were found.

The present study showed that the quantitative analysis presented morphological changes of intestinal villus after ischemia and reperfusion, and that these alterations were not detected in the qualitative analysis, although it was demonstrated that the epithelium is regenerated from the qualitative point of view. When quantitatively analyzed, it was detected significant histopathological changes after 24 hours reperfusion, such as decreased length and increased width. It is important the fact of finding an increased percentage of nucleuses in mitosis (mitotic index) in epithelia submitted to ischemia and reperfusion, after 24 hours, in the process of regeneration. It should be emphasized that it is statistically significant when group III was compared to group I (control). In this way, the findings disorders of mesenteric lymph flow and in vivo intestinal lymphocytes migration and the accompanying increase of endotoxin and TNF-alpha levels in mesenteric lymph, and the lymph drainage could block the "gutlymph" pathway, improve intestinal barrier function, and attenuate distant organ injury in the early stage of gut I/R injury ${ }^{34,35}$. The intestinal post ischemic perfusion with hypertonic saline through the superior mesenteric artery followed by blood flow restoration is a protective procedure that could be used for the prevention of intestinal ischemia and reperfusion injury ${ }^{36}$.

Through comparisons between groups, it can be inferred that the villus regeneration by mitosis begins immediately after ischemic injury caused in the villus. In addition to the qualitative and quantitative histopatological changes already observed, several studies showed biochemical and inflammatory alterations after ischemia and specially reperfusion ${ }^{14,27,37-40}$ Some authors think that the preconditioning protection revealed significant evidence against small bowel wall of ischemia-reperfusion injury and attenuate the permeability of the small intestines after limb ischemia-reperfusion. The protective mechanism of ischemic post-conditioning may be related to inhibition of oxygen free radicals and inflammatory cytokines that cause organ damage ${ }^{41-45}$.

The studies of Parks et al. ${ }^{11}$, Horton et al. ${ }^{12}$ and Van Ye et $a l .{ }^{15}$ about the importance of free radicals in the injuries caused by ischemia and reperfusion allowed the understanding of the process of these changes, and contributed to an effective action to reduce the harmful effects triggered by them.

Among these performances several drugs have been and are being used, such as "chelating" free radicals and antioxidants substances which provide evidence in reducing injuries caused by the ischemia and reperfusion, as well as extending the length of bowel tolerance time to this process ${ }^{3,17-19,40,46}$. Also the hyperbaric oxygen therapy can limit tissue damage due to ischemia/ reperfusion injury, by inducing reparative signaling pathways ${ }^{47}$.

Recently the studies are demonstrating the use of gene therapy submucosal infusion of mesenchymal stem cells (MSCs) might exert to show how it is possible to obtain benefits in the prevention of injuries brought about by the process of ischemia and reperfusion ${ }^{48,49}$.

The present study demonstrated the importance of performing quantitative analysis to evaluate the changes caused by ischemia and reperfusion, whereas the qualitative analysis may not be sufficient to define these changes. It should be stressed the need to consider morphological changes (quantitative) and mitotic index to evaluate the results of various forms of treatment that can minimize the consequences of the ischemia and reperfusion.

\section{Conclusion}

The epithelium is regenerated, when subjected to different time planned of ischemia and reperfusion. It was observed: decrease the length and increase the width of the villi, when compared Group VI with I and II, and Group VI with I; increased mitotic index when compared Groups III with I. Every analysis was statistically significant.

\section{References}

1. Camargo LM, Neto JE, Freitas SH, Simões MJ, Gomes PO, Sébe AA. Ultrastructural aspects of the intestinal villi after hepatic pedicle clumping in rats. Acta Cir Bras. 2003;18(6):542-4.

2. Varga J, Tóth S Jr, Tóth S, Tomečková V, Gregová K, Veselá J, The relationship between morphology and disaccharidase activity in ischemia- reperfusion injured intestine. Acta Biochim Pol. 2012;59(4):631-8. 
3. Zhang T, Wang Y, Ban R, Tong L, Qiao H, Lao H, Zhao H, Jiang $X$, Sun X, Zhang F. Oral administration of lactoferrin attenuates intestinal ischemia-reperfusion injury in rats. Eur Surg Res. 2012;49(2):99-106.

4. Chiu JC, Mcardle AH, Brown R, Scott JH, Gurd NF. Intestinal mucosal lesion in low-flow states. A morphological, hemodynamic and metabolic reappraisal. Arch Surg. 1970;101:478-83.

5. Haglund $U$, Lundgren $O$. Reactions within consecutive vascular sections of the small intestine of the cat during prolonged hypotension. Acta Physicol.Scand. 1972;84:151-61.

6. Battelli MG, Della Corte E, Stirpe E. Xanthine oxidase type D (dehydrogenase) in the intestine and other organs of the rat. Biochem J. 1972;26:404-27.

7. Scannell G, Waxman K, Vaziri ND, Zhang J, Kaupke CJ, Jalali M, Hecht CC. Hypoxia-induced alterations of neutrophil membrane receptors. J Surg Res. 1995;59(1):141-5.

8. Pinheiro BV, Holanda MA, Araújo FG, Romaldini H. Lesão pulmonar de reperfusão. J Pneumol. 1999;25(2):124-36.

9. Meyer TN, Silva AL. Cellular response to stress. J Braz Med Assoc. 1999;45(2):181-8.

10. Lundgren $\mathrm{O}$, Haglund $U$. The pathophysiology of the intestinal countercorrent exchanger. Life Sel. 1978;23:1411-22.

11. Parks DA, Bulkley GB, Neil Granger D, Hamilton-Stanley R, Mccord Joe M. Ischemic injury in the cast small intestine: role of superoxide radicals. Gastroenterology. 1982;82:9-15.

12. Horton JW, Walker PB. Oxygen radicals, lipid peroxidation and permeability changes after intestinal ischemia and reperfusion. J Appl Physiol. 1993;74(4):1515-20.

13. Grisham MB, Hernandez LA, Granger DN. Xanthine oxidase and neutrophil infiltration in intestinal ischemia. Am J Physiol. 1986;251:567-74.

14. Kubes P, Ibbotson G, Russell J, Wallace JL, Granger DN. Role of platelet-activating factor in ischemia/reperfusion-induced leukocyte adherence. Am J Physiol. 1990;259:300-5.

15. Van Ye TM, Roz AM, Pieper G.M, Henderson J JR, Johnson CP, Adams MB. Inhibition of intestinal lipid peroxidation does not minimize morphologic damage. J Surg Res. 1993;55(5):553-8.

16. Boorstein JM, Dacey LJ, Cronenwett JL. Phamacologic treatment of occlusive mesenteric ischemia in rats. J Surg Res. 1998;44(5):55560.

17. Bilbao J, Garcia Alonso I, Portugal V, Barcelo P, Ortiz J, Ndez J. Therapeutic usefulness of antioxidant drugs in experimental intestinal reperfusion syndrome. Rev Esp Enfer Dig. 1991;80(4):237-41.

18. Lehmann C, Luther B, Holz A, Roth S, David H, Grune T, Siems W, Burger K, Kox WJ. Perioperative vascular flushing perfusion in acute mesenteric artery occlusion. Eur J Vasc Envasc Surg. 1995;10 (3):265-71.

19 Schleiffer R, Raul F. Prophylatic administration of L-arginine improves the intestinal barrier function after mesenteric ischemia. Gut. 1996;39(2):194-8.

20. Deshmukh DR, Mirochnitchencko O, Ghole VS, Agnese D, Shah PC, Redelli M, Brolin RE, Inouye M. Intestinal ischemia and reperfusion injury in transgenic mice over expressing copper-zinc superoxid dismutase. Am J Physiol. 1997;273:130-5.

21.Nakamura M, Ozaki M, Fuchino S, Teraoka S, Ota K. Ascorbic acid prevents ischemia-reperfusion injury in the rat small intestine. Transplant Int. 1997;10(2):89-95.

22. Haddad MA, Miranda-Ferreira R, Taha NS, Maldonado VC, Daroz RR, Daud MO, Neto JL, Muniz DA, Silva PC, Monteiro HP, Fagundes DJ, Caricati-Neto A, Taha MO. Effect of adenosine on injury caused by ischemia and reperfusion in rats: functional and morphologic study. Transplant Proc. 2012;44(8):2317-20.
23. Ghadie MM, Miranda-Ferreira R, Taha NS, Maroso AS, Moreti RJ, Andraus MP, Zempulski P, Monteiro HP, Simões MJ, Fagundes DJ, Caricati-Neto A, Taha MO. Study of heparin in intestinal ischemia and reperfusion in rats: morphologic and functional evaluation. Transplant Proc. 2012;44(8):2300-3.

24. Guzmán-De La Garza FJ, Cámara-Lemarroy CR, Ballesteros-Elizondo RG, Alarcón-Galván G, Cordero-Pérez P, Fernández-Garza NE. Ketamine reduces intestinal injury and inflammatory cell infiltration after ischemia/reperfusion in rats. Surg Today. 2010;40(11):105562.

25. Granger DN, Hollwarth ME, Parks DA. Ischemia-reperfusion injury: role of oxygen-derived free radicals. Acta Physiol Scand. 1986;548:47-63.

26. Ruke RPC, Gart R. Epithelial cell kinetics in the descending colon of rat. Virchows Arch B Cell Pathol. 1979;31:15-22.

27. Hernandez LA, Grisham MB, Twohig B, Arfors KE, Harlan JM, Neil Granger D. Role of neutrophils in ischemia-reperfusion induced micro vascular injury. Am J Physiol. 1987;253:699-703.

28. Granger DN, Rutili G, Mccord JM. Superoxide radicals in feline ischemia. Gastroenterology. 1981;81:22-9.

29. Patel A, Kaleya RN, Sammartano RJ. Pathology of mesenteric ischemia. Surg Clin North Am. 1992;72:31-41.

30. Illy SG, Hamar J. Sequence of morphological alterations in a small intestinal ischemia / Reperfusion model of the anesthetized rat. A light microscopy study. Int J Exp Pathol. 1992;73(2):161-72.

31. Udassin R, Vromen A, Haskel Y. The time sequence of injury and recovery following transient reversible intestinal ischemia. J Surg Res. 1994;56(3):221-5.

32. Bounus G. Acute necrosis of the intestinal mucosa. Gastroenterology. 1982;82:1457-67.

33. Zambetis M, Grossman HJ. Effect of ischaemia on endotheliumdependent vasodilatation in the isolated rat superior mesenteric artery. Br J Exp Pathol. 1988;69(1):81-90.

34. Yang H, Jin Y, Li M, Wang CH, Tang CW. Disturbances of mesenteric lymph flow and in vivo intestinal lymphocyte trafficking during early gut injury induced by ischemia-reperfusion in rats. Lymphology. 2012;45(3):130-9.

35. He GZ, Zhou KG, Zhang R, Wang YK, Chen XF. Impact of intestinal ischemia/reperfusion and lymph drainage on distant organs in rats. World J Gastroenterol. 2012;18(48):7271-8.

36. Kornyushin O, Galagudza M, Kotslova A, Nutfullina G, Shved N, Nevorotin A, Sedov V, Vlasov T. Intestinal injury can be reduced by intra-arterial postischemic perfusion with hypertonic saline. World J Gastroenterol. 2013;19(2):209-18.

37. Van Ye TM, Roz AM, Pieper G.M, Henderson J JR, Johnson CP, Adams MB. Inhibition of intestinal lipid peroxidation does not minimize morphologic damage. J Surg Res. 1993;55(5):553-8.

38. Siems W, Grune T, Lehmann C, Gemkow O, Ansorge K, Luther B, Gerber G. Superoxide dismutase promotes ATP and GTP restoration of rat small intestine during post ischemic reperfusion. Pharmazie. 1991;46(10):735-7.

39. Fujimoto K, Granger DN, Price VH, Tso P. Ornithine descarboxylase in involved in repair of small intestine after ischemia-reperfusion in rats. Am J Physiol. 1991;261(3pt 1):G523-9.

40. Langer JC, Sohal SS. Increased mucosal permeability after intestinal ischemia- reperfusion is mediate by local tissue factors. J Pediatr Surg. 1992;27:329-32.

41. Gomes OM, Brasileiro Filho G, Salles RL, Linhares RE, Nazar MC, Porto LA, Paixão RM, Miranda MH. Ischemia-reperfusion histopathology alterations of the rabbit intestinal wall with and without ischemic preconditioning. Acta Cir Bras. 2011; 26(4):285-8. 
42. Santos CHM, Gomes OM, Pontes JCDV, Miiji LNO, Bispo MAF. The ischemic preconditioning and postconditioning effect on the intestinal mucosa of rats undergoing mesenteric ischemia/ reperfusion procedure Acta Cir Bras. 2008;23(1):22-8.

43. Mallick IH, Yang W, Winslet MC, Seifalian AM. Protective effects of ischemic preconditioning on the intestinal mucosal microcirculation following ischemia-reperfusion of the intestine. Microcirculation. 2005;12(8):615-25.

44. Leng YF, Zhang Y, Zhang Y, Xue X, Wang T, Kang YQ. Ischemic post-conditioning attenuates the intestinal injury induced by limb ischemia/reperfusion in rats. Braz J Med Biol Res. 2011;44(5):4117.

45. Liu KX, Li YS, Huang WQ, Chen SQ, Wang ZX, Liu JX, Xia Z. Immediate postconditioning during reperfusion attenuates intestinal injury. Intensive Care Med. 2009;35(5):933-42.

46. Lefer DJ, Scalia R, Campbell B, Nossuli T, Hayward R, Salamon M, Grayson J, Lefer AM. Peroxynitrite inibits leucocyte-endothelial cell interactions and protects against ischemia-reperfusion injury in rats. J Clin Invest. 1997;99(4):684-91.

47. Daniel RA, Cardoso VK, Góis Jr E, Parra RS, Garcia SB, Rocha JJ, Féres O. Effect of hyperbaric oxygen therapy on the intestinal ischemia reperfusion injury. Acta Cir Bras. 2011;26(6):463-9.

48. Yagihashi A, Tsuruma T, Tarumi K, Kameshima T, Yajima T, Yanai Y, Watanabe N, Hirat K. Prevention of small intestinal ischemiareperfusion injury in rat by anti-cytokine induced neutrophil chemo attractant monoclonal antibody. J Surg Res. 1998;78(2):92-6.

49. Jiang H, Qu L, Li Y, Gu L, Shi Y, Zhang J, Zhu W, Li J. Bone marrow mesenchymal stem cells reduce intestinal ischemia/reperfusion injuries in rats. J Surg Res. 2011;168(1):127-34.

\section{Acknowledgments}

To Cristina Tanikawa, pharmaceutics, for the support experimental research and cooperation to edit this article

\section{Correspondence:}

Ana Terezinha Guillaumon

Rua Hermantino Coelho, 901/11

13087-500 Campinas - SP Brasil

Tel.: (55 19)3521-7133terag@fcm.unicamp.br/terag@ig.com.br

Received: December 18, 2012

Review: February 20, 2013

Accepted: March 19, 2013

Conflict of interest: none

Financial source: none

1Research performed at Microprocedures and Vascular Research Laboratory, Medical Sciences School, State University of Campinas (UNICAMP), Brazil. Part of PhD degree thesis, Postgraduate Program in Surgery Sciences. Tutor: Profa. Ana Terezinha Guillaumon. 